\title{
White blood cell count and all-cause and cause-specific mortality in the Guangzhou biobank cohort study
}

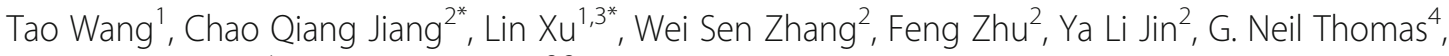
Kar Keung Cheng ${ }^{4}$ and Tai Hing Lam ${ }^{2,3}$

\begin{abstract}
Background: Several studies have shown positive associations between higher WBC count and deaths from allcauses, CHD, stroke and cancer among occidental populations or developed countries of Asia. No study on the association of WBC count with all-cause and cause-specific mortality in Chinese populations was reported. We studied this using prospective data from a large Chinese cohort.
\end{abstract}

Methods: We used prospective data from the Guangzhou Biobank Cohort Study (GBCS), a total of 29,925 participants in present study. A Cox proportional hazards regression model was used to estimate the hazard ratios (HR) and 95\% confidence interval (Cl).

Results: The hazard ratios (HR) for all-cause, CHD, and respiratory disease mortality for the highest decile of WBC count (women $>8.2 \times 10^{9} / \mathrm{L}$; men $>8.8 \times 10^{9} / \mathrm{L}$ ) was 1.83 (95\% confidence interval $\left.(\mathrm{Cl}) 1.54,2.17\right)$ ) 3.02 (95\% Cl 1.84, 4.98 ) and 2.52 (95\% Cl 1.49, 4.27), respectively, after adjusting for multiple potential confounders. The associations were similar when deaths during the first 2 years of follow-up were excluded. After further adjusting for pulmonary function, the highest decile of WBC count was associated with 90\% higher risk of respiratory disease mortality (HR 1.90, 95\% Cl 1.08, 3.33). No evidence for an association between higher WBC count and cancer mortality was found. Sub-type analysis showed that only granulocyte count remained significantly predictive of all-cause, CHD, and respiratory disease mortality.

Conclusions: Elevated WBC, specifically granulocyte, count was associated with all-cause, CHD and respiratory mortality in southern Chinese. Further investigation is warranted to clarify whether decreasing inflammation would attenuate WBC count associated mortality.

Keywords: White blood cell count, Granulocyte count, Cause-specific mortality, All-cause mortality, Prospective cohort study

\section{Background}

In clinical practice, the circulating white blood cell (WBC) count is readily available and widely used as an indicator of systemic inflammation. Numerous studies have shown positive associations between higher WBC count and deaths from all-causes [1-4], coronary heart disease (CHD) [5], stroke [6] and cancer [7]. Most of

\footnotetext{
* Correspondence: jcqiang@163.com; xulin27@mail.sysu.edu.cn

${ }^{2}$ Guangzhou No.12 Hospital, Guangzhou 510620, China

${ }^{1}$ School of Public Health, Sun Yat-sen University, 2nd Zhongshan

RoadGuangdong Province, Guangzhou, China

Full list of author information is available at the end of the article
}

these studies were conducted in high-income countries of Asia [3, 4] or in the West [1, 2, 5-7]. Ethnic differences in WBC count exist, whereby reference intervals (RIs) for both Americans of Chinese and African origin are lower than those of European and Mexican origin [8]. Moreover, populations with different ethnicities may underlie different patterns of confounding factors (i.e., lifestyle and demographic factors), and an association consistently observed in different settings with different sets of confounders suggests that such association may be real or causal. Given this, and that no study describing the association between WBC count and mortality

(c) The Author(s). 2018 Open Access This article is distributed under the terms of the Creative Commons Attribution 4.0 International License (http://creativecommons.org/licenses/by/4.0/), which permits unrestricted use, distribution, and reproduction in any medium, provided you give appropriate credit to the original author(s) and the source, provide a link to the Creative Commons license, and indicate if changes were made. The Creative Commons Public Domain Dedication waiver (http://creativecommons.org/publicdomain/zero/1.0/) applies to the data made available in this article, unless otherwise stated. 
in Chinese populations was reported, we studied this association for all-cause, CHD, cancer, and respiratory disease mortality using prospective data from the Guangzhou Biobank Cohort Study.

As previous studies suggested an adverse association between pulmonary function and WBC count $[9,10]$, we hypothesized that this may account for any association between increased WBC count and higher risk of respiratory disease mortality. To examine whether such association, if any, could be attributable to pulmonary function we adjusted for pulmonary function and self-reported pulmonary disease in the analysis of respiratory disease mortality. We also examined the association for sub-types of WBC.

\section{Methods}

\section{Study subjects}

Participants of the Guangzhou Biobank Cohort Study (GBCS) were recruited from September 2003 to January 2008. Details of GBCS were described elsewhere [11]. Briefly, GBCS is a 3-way collaboration among the Guangzhou Number 12 Hospital in Guangzhou, China, the University of Hong Kong in Hong Kong, and the University of Birmingham in the UK. Participants was recruited from the "Guangzhou Health and Happiness Association for the Respectable Elders" (GHHARE), a community social and welfare organization unofficially aligned with the municipal government. Membership is open to Guangzhou permanent residents aged $50+$ years for a nominal fee of $4 \mathrm{CNY}$ ( $\approx 50$ US cents) per month. GHHARE included about $7 \%$ of Guangzhou residents in this age group, with branches in all districts of Guangzhou, the capital city of Guangdong Province in southern China.

\section{Ethical approval}

The GBCS was approved by Guangzhou Medical Ethics Committee of the Chinese Medical Association. All participants provided written, informed consent before participation.

\section{Data collection and variable definition}

The baseline examination included an interview about demographic characteristics, lifestyle (smoking and alcohol use), family and personal medical history and assessment of weight, height, blood pressure, fasting plasma glucose, lipids and inflammatory markers. Body mass index was calculated by body weight $(\mathrm{kg})$ divided by height (m) squared. Physical activity was assessed by the Chinese version of International Physical Activity Questionnaire (IPAQ) and was classified into inactive, moderately active and physically active. Reliability and validity of the questionnaire was tested by recalling 200 randomly selected subjects for re-interview. The Kappa values for the following selected questions were: self-reported vascular disease (0.66), smoking (0.96 and 0.88 for the two questions on smoking status), drinking (0.60), education (0.90), and occupation $(0.80)$ [12, 13]. Forced expiratory volume in $1 \mathrm{sec}$ (FEV1) and forced vital capacity (FVC) were measured using spirometry [14]. Fasting blood samples were obtained from all participants at baseline and were analyzed for WBC count (KX-21, SYSMEX, Japan), counts of WBC sub-types, glucose, lipids and other common biochemical parameters.

\section{Mortality}

Information on underlying causes of deaths up to January 2016 was mostly obtained via record linkage with the Guangzhou Center for Disease Control and Prevention (GZCDC). Causes of death were coded according to the 10th revisions of the International Classification of Diseases (ICD) by trained nosologists in each hospital. Cancer types included: breast, liver, stomach, colorectal and lung cancer. When the death certificates were not issued by medical institutions (and hence might have quality issue with the coding), the causes of death were verified by GZCDC as part of their quality assurance programme by cross-checking past medical history and conducting verbal autopsy. In addition, from August 2015 to May 2016, ten verbal autopsy meetings were conducted in the Guangzhou 12th Hospital to further clarify the deaths with unclear causes. A physician panel including 5 chief physicians from various disciplines reviewed all available medical records of the same individuals and assigned in a standard manner a cause of death, with assistance of an epidemiologist for unsettled cases. When participants were confirmed dead but the exact dates of death were not available, the mid-point between the date of recruitment and 31 January 2016 was used $(n=6)$.

\section{Statistical analysis}

Chi-square tests or analysis of variance was used to compare participants' baseline characteristics by deciles of baseline WBC count. We used Cox proportional hazards models to assess the association of deciles of baseline WBC count with all-cause and cause-specific mortality. We checked the Cox proportional assumption using Schoenfeld residuals by "stphtest" command in Stata. As we found no evidence for the violation of the proportional hazard assumption, the Cox proportional hazards model was used, giving hazard ratios (HRs) and 95\% confidence intervals (CI). To enable comparison with previous studies $[1,15]$, we analyzed WBC count deciles and selected the decile group with the lowest mortality rate as the reference group. We also compared models using different WBC count cut-off points (i.e., tertiles, quartiles or quintiles) in terms of their fitness and found that the model using WBC count deciles had the lowest Akaike information criterion value, indicating a satisfactory fitness. Follow-up time was calculated as 
days from enrollment to death or the end of follow-up. Covariates included in the main model were age (years), sex (women; men), education (primary or below; secondary; college or above), occupation (manual; non-manual; or others), smoking status (never; former; or current smokers), alcohol use (never; former; or current drinkers), physical activity (inactive; moderate; or active), self-rated health (very poor; poor; good; and very good), body mass index $\left(\mathrm{kg} / \mathrm{m}^{2}\right)$, diabetes (yes/no), triglycerides and high-density lipoprotein cholesterol $(\mathrm{mmol} / \mathrm{l})$, platelet count $\left(10^{9} / \mathrm{l}\right)$ and haemoglobin $(\mathrm{g} / \mathrm{l})$.

Sensitivity analysis was performed by excluding deaths occurred within the first 2 years. For the association of WBC count with respiratory disease mortality, because the association might be confounded by poor lung function, we further adjusted for pulmonary function, as indicated by FVC and FEV1, and self-reported respiratory disease including COPD, chronic bronchitis, emphysema, asthma, tuberculosis, pneumonia. We also tested for an interaction between smoking status and WBC counts using likelihood ratio test to test for the fitness of models with or without the interaction terms. Models with a lower Akaike information criterion (AIC) or Bayesian information criterion (BIC) value indicate better fitness. We found no evidence of interaction between smoking status and WBC count for the risk of all-cause and cause-specific mortality ( $P$ values for interaction from 0.34 to 0.99 ). However, as smoking plays a significant role in respiratory disease mortality and mortality due to many other causes, and in other underlying illnesses which can lead to some inflammation, we conducted sensitivity analyses in never or ever- (including former and current) smokers to minimize potential confounding. Furthermore, as a WBC count of less than $4 \times 10^{9} / \mathrm{L}$ may clinically be an indicator of leucopenia and a WBC count of greater than $10 \times 10^{9} / \mathrm{L}$ may indicate an elevated inflammatory response, we also conducted sensitivity analyses including participants with a WBC count within the normal range only, as per the internationally recognized criteria for abnormal WBC count (i.e., WBC count $<4 \times 10^{9} / \mathrm{L}$ or $>$ $10 \times 10^{9} / \mathrm{L}$ ), to minimize the confounding effect due to these underlying diseases. We also did similar analysis for WBC subtypes. All statistical analysis was performed using Stata/IC 14.0.

\section{Results}

Of 30,430 participants at baseline, 391 were excluded because of loss to follow-up with unknown vital status and 202 excluded because of incomplete information on WBC count, giving 29,925 participants (21,648 women and 8277 men) in the present analysis. The mean age at baseline was 62 (standard deviation (SD) 7.1) years. During the average follow-up of 9.3 (SD 1.9) years, 2979 deaths (women 1581 (7.3\%); men 1398 (16.9\%)) were recorded.
Table 1 shows that the proportion of current smokers increased with increasing deciles of WBC count. Higher BMI, triglycerides, haemoglobin and platelet count were positively, while HDL-cholesterol, FEV1 and FVC was inversely associated with WBC count decile, but current alcohol drinking, physical activity and self-rated health, or age (as a continuous variable) were not.

For both all-cause and CHD mortality, the 4th decile group (i.e., WBC count of $5.4-5.6 \times 10^{9} / \mathrm{L}$ in women and $5.8-6.0 \times 10^{9} / \mathrm{L}$ in men) had the lowest mortality rate. Hence, the 4th decile group was used as the reference. Table 2 shows that greater WBC count was associated with both all-cause and CHD mortality in multivariable adjusted models, and the associations were slightly attenuated but remained statistically significant when the deaths in the first 2 years of follow-up were excluded. Relative to the 4th decile, the adjusted HRs for both all-cause and CHD mortality increased substantially in the highest decile (women $>8.2 \times 10^{9} / \mathrm{L}$; men $>8.8 \times 10^{9} / \mathrm{L}$; HR 1.83 (95\% CI 1.54, 2.17) and $3.02(1.84,4.98)$, respectively).

For cancer mortality and respiratory disease mortality, the lowest mortality rate was observed in the 3rd decile group (i.e., WBC count of $4.9-5.3 \times 10^{9} / \mathrm{L}$ in women and $5.3-5.7 \times 10^{9} / \mathrm{L}$ in men), which was used as the reference group in the subsequent analyses. Table 3 shows that, relative to the 3rd decile group, participants in the lower decile (1st or 2nd) showed a higher risk for cancer mortality, and the HR was statistically significant for the 2nd decile (HR 1.54, 95\% CI 1.17, 2.03). Greater WBC count showed no association with cancer mortality. We found positive associations between higher deciles of WBC count and respiratory disease mortality in the multivariable adjusted models, and the associations were unchanged after excluding deaths within the first 2 years of follow-up (Table 3). After further adjustment for pulmonary function and respiratory disease history including COPD, chronic bronchitis, emphysema, asthma, tuberculosis, pneumonia, the associations were attenuated slightly but remained statistically significant (HR 1.90, 95\% CI 1.08, 3.33). After excluding current and former smokers, the results were similar (Table 4).

Sensitivity analysis showed that, after excluding participants with abnormal WBC count, or restricting data analysis to current smokers only, the results showing that greater WBC count was associated with increased respiratory disease mortality were similar (Additional file 1: Tables S1-S4). Another sensitivity analysis examining the association of subtypes of WBC (i.e., granulocyte or lymphocyte count) with mortality showed that participants with higher granulocyte count $(>5.44 \times$ $10^{9} / \mathrm{L}$ ) were associated with $45 \%, 69 \%$ and 1.6 -fold higher risk of mortality from all-cause, CHD and respiratory disease, respectively, but not associated with cancer mortality (Additional file 1: Tables S5-S6). 


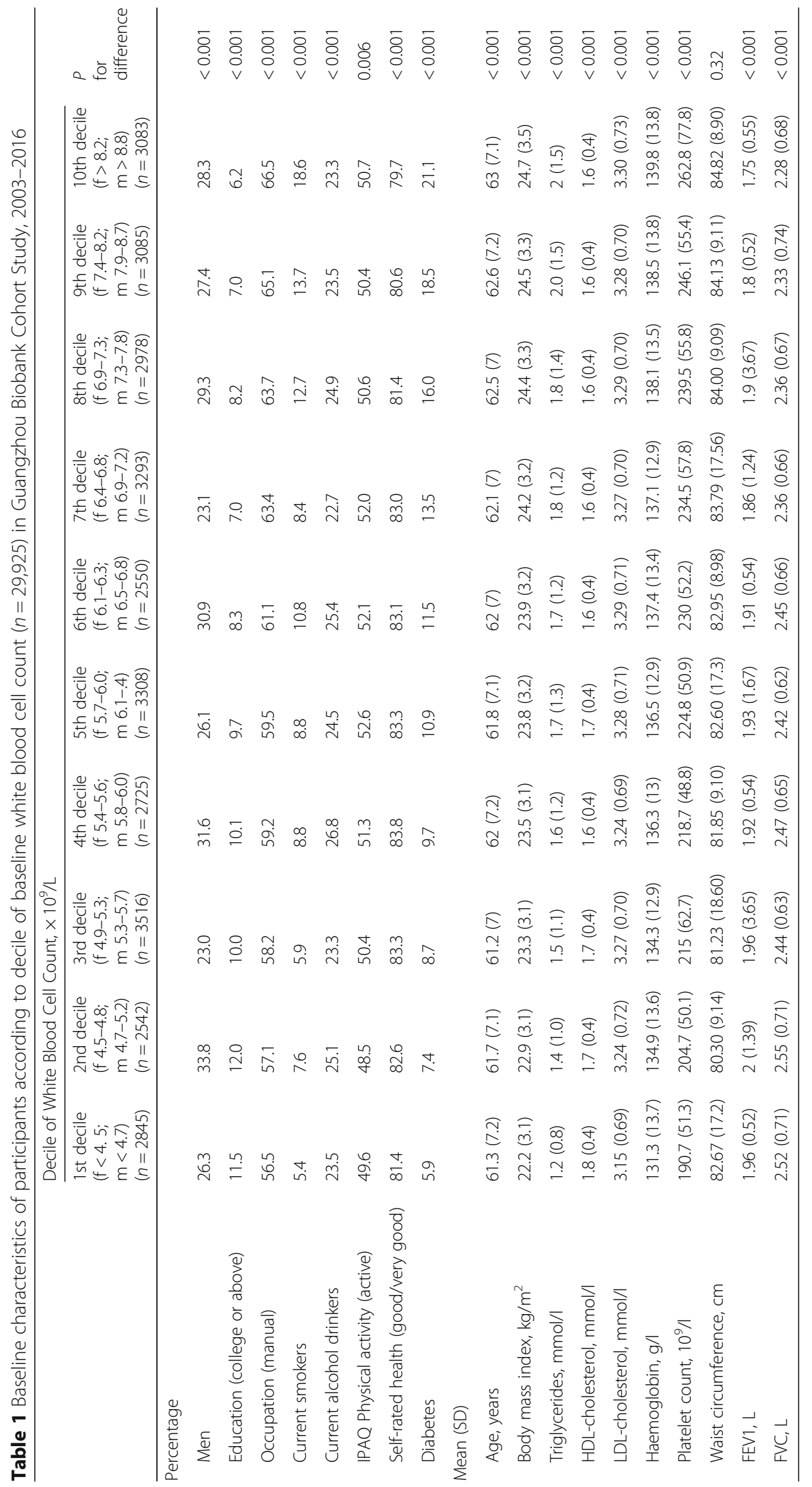


Table 2 Association between baseline white blood cell count and total mortality and coronary heart disease (CHD) mortality in the Guangzhou Biobank Cohort Study, 2003-2016

\begin{tabular}{|c|c|c|c|c|c|c|}
\hline \multirow[t]{2}{*}{$\begin{array}{l}\text { Decile of WBC count, } \\
\times 10^{9} / L \text { (range) }\end{array}$} & \multicolumn{2}{|c|}{$\begin{array}{l}\text { Age, sex-adjusted } \\
\text { results }(n=29,925)\end{array}$} & \multicolumn{2}{|c|}{$\begin{array}{l}\text { Multivariable adjusted }^{a} \\
(n=29,925)\end{array}$} & \multicolumn{2}{|c|}{$\begin{array}{l}\text { Further excluding deaths } \\
\text { within } 2 \text { years }{ }^{\mathrm{a}}(n=29,672)\end{array}$} \\
\hline & $\mathrm{HR}(95 \% \mathrm{Cl})$ & $P$ value & HR $(95 \% \mathrm{Cl})$ & $P$ value & HR $(95 \% \mathrm{Cl})$ & $P$ value \\
\hline \multicolumn{7}{|l|}{ Total mortality (no. of deaths $=2997$ ) } \\
\hline 1st decile ( $<<4.5 ; \mathrm{m}<4.7$ ) & $1.36(1.14,1.63)$ & 0.001 & $1.31(1.09,1.58)$ & 0.005 & $1.20(0.99,1.46)$ & 0.07 \\
\hline 2nd decile (f 4.5-4.8; m 4.7-5.2) & $1.32(1.10,1.58)$ & 0.003 & $1.33(1.10,1.60)$ & 0.003 & $1.26(1.04,1.53)$ & 0.02 \\
\hline 3rd decile (f 4.9-5.3; m 5.3-5.7) & $1.06(0.88,1.28)$ & 0.51 & $1.05(0.87,1.27)$ & 0.63 & $0.97(0.80,1.18)$ & 0.77 \\
\hline 4th decile (f 5.4-5.6; m 5.8-6.0) & Reference & & Reference & & Reference & \\
\hline 5th decile (f 5.7-6.0; m 6.1-.4) & $1.30(1.09,1.54)$ & 0.004 & $1.29(1.08,1.55)$ & 0.005 & $1.21(1.00,1.46)$ & 0.04 \\
\hline 6th decile (f 6.1-6.3; m 6.5-6.8) & $1.13(0.94,1.37)$ & 0.20 & $1.14(0.94,1.38)$ & 0.20 & $1.09(0.90,1.34)$ & 0.38 \\
\hline 7th decile (f 6.4-6.8; m 6.9-7.2) & $1.36(1.14,1.62)$ & 0.001 & $1.36(1.13,1.63)$ & 0.001 & $1.28(1.06,1.53)$ & 0.009 \\
\hline 8th decile (f 6.9-7.3; m 7.3-7.8) & $1.56(1.31,1.85)$ & $<0.001$ & $1.50(1.26,1.79)$ & $<0.001$ & $1.41(1.17,1.69)$ & $<0.001$ \\
\hline 9th decile (f 7.4-8.2; m 7.9-8.7) & $1.68(1.42,1.99)$ & $<0.001$ & $1.58(1.32,1.88)$ & $<0.001$ & $1.48(1.23,1.77)$ & $<0.001$ \\
\hline 10th decile ( $f>8.2 ; m>8.8$ ) & $1.96(1.66,2.31)$ & $<0.001$ & $1.83(1.54,2.17)$ & $<0.001$ & $1.72(1.44,2.05)$ & $<0.001$ \\
\hline \multicolumn{7}{|l|}{ CHD mortality (no. of deaths $=459)^{b}$} \\
\hline 1st decile ( $f<4.5 ; \mathrm{m}<4.7$ ) & $1.48(0.85,2.57)$ & 0.16 & $1.54(0.87,2.71)$ & 0.14 & $1.48(0.84,2.61)$ & 0.18 \\
\hline 2nd decile (f 4.5-4.8; m 4.7-5.2) & $1.20(0.67,2.15)$ & 0.55 & $1.28(0.70,2.31)$ & 0.42 & $1.22(0.67,2.22)$ & 0.52 \\
\hline 3rd decile (f 4.9-5.3; m 5.3-5.7) & $1.47(0.86,2.52)$ & 0.16 & $1.40(0.80,2.44)$ & 0.24 & $1.40(0.80,2.43)$ & 0.24 \\
\hline 4th decile (f 5.4-5.6; m 5.8-6.0) & Reference & & Reference & & Reference & \\
\hline 5th decile (f 5.7-6.0; m 6.1-.4) & $1.51(0.89,2.57)$ & 0.13 & $1.48(0.86,2.55)$ & 0.16 & $1.34(0.77,2.34)$ & 0.30 \\
\hline 6th decile (f 6.1-6.3; m 6.5-6.8) & $1.58(0.91,2.74)$ & 0.11 & $1.58(0.90,2.78)$ & 0.11 & $1.60(0.91,2.81)$ & 0.10 \\
\hline 7th decile (f 6.4-6.8; m 6.9-7.2) & $1.85(1.11,3.10)$ & 0.02 & $1.78(1.05,3.02)$ & 0.03 & $1.74(1.02,2.95)$ & 0.04 \\
\hline 8th decile (f 6.9-7.3; m 7.3-7.8) & $2.40(1.46,3.95)$ & 0.001 & $2.27(1.36,3.78)$ & 0.002 & $2.13(1.27,3.56)$ & 0.004 \\
\hline 9th decile (f 7.4-8.2; m 7.9-8.7) & $1.74(1.03,2.93)$ & 0.04 & $1.62(0.95,2.78)$ & 0.08 & $1.56(0.90,2.68)$ & 0.11 \\
\hline 10th decile $(f>8.2 ; m>8.8)$ & $3.45(2.15,5.55)$ & $<0.001$ & $3.02(1.84,4.98)$ & $<0.001$ & $2.86(1.73,4.73)$ & $<0.001$ \\
\hline
\end{tabular}

a adjusted for age, sex, education, occupation, smoking status, alcohol use, physical activity, self-rated health, body mass index, diabetes, triglycerides, highdensity lipoprotein cholesterol, platelet count and haemoglobin

b 1528 participant with vascular disease at baseline including coronary heart disease, stroke, angina, myocardial infarction and peripheral vascular disease were excluded

However, no association between lymphocyte count and mortality was found (Additional file 1: Tables S7-S8).

\section{Discussion}

In this understudied population, high WBC count was robustly associated with all-cause, $\mathrm{CHD}$ and respiratory disease mortality after adjusting for potential confounders. The significant association between high WBC count and respiratory disease mortality supports our hypothesis that an increased in WBC count predicts a higher risk of respiratory disease mortality, independently of smoking and pulmonary function.

WBC count is a standardized and accurate measurement that has been used in epidemiologic studies as a predictor of mortality from all- and specific causes in the general population $[1,3,4,16,17]$, or a predictor of specific outcomes in hospital-based studies of patients [18-21]. Our results on all-cause and CHD mortality are consistent with those from other settings $[1,3,4]$. The association of WBC count with cardiovascular risk or mortality has been well described in studies that have focused on western or economically-developed Asian populations [2-5, 22]. Such association persists after adjustment for multiple cardiovascular risk factors including smoking, an important confounder of the WBC-mortality association [23]. We found no evidence for an interaction between smoking and WBC count, which is in agreement with previous studies [23, 24], supporting an independent association between WBC count and risk of $\mathrm{CHD}$ in smokers and in non-smokers. Elevated WBC count may affect CHD through a number of possible pathologic mechanisms, such as altering endothelial function [25], attenuating nitric oxide and prostacyclin production [26] and consequently reducing the vasodilatory, antithrombotic and anti-atherogenic properties of the vascular endothelium $[27,28]$. Increased adherence of stimulated WBC to the vascular endothelium promotes capillary leukocytosis and subsequent increased vascular resistance [29]. 
Table 3 Association between the baseline white blood cell count and cancer and respiratory disease mortality in the Guangzhou Biobank Cohort Study, 2003-2016

\begin{tabular}{|c|c|c|c|c|c|c|}
\hline \multirow[t]{2}{*}{$\begin{array}{l}\text { Decile of WBC count, } \\
\times 10^{9} / \mathrm{L} \text { (range) }\end{array}$} & \multicolumn{2}{|c|}{$\begin{array}{l}\text { Age, sex-adjusted } \\
\text { results }(n=29,925)\end{array}$} & \multicolumn{2}{|c|}{$\begin{array}{l}\text { Multivariable adjusted } \\
(n=29,925)\end{array}$} & \multicolumn{2}{|c|}{$\begin{array}{l}\text { Further excluding deaths } \\
\text { within } 2 \text { years }{ }^{a}(n=29,672)\end{array}$} \\
\hline & $\mathrm{HR}(95 \% \mathrm{Cl})$ & $P$ value & $\mathrm{HR}(95 \% \mathrm{Cl})$ & $P$ value & $\mathrm{HR}(95 \% \mathrm{Cl})$ & $P$ value \\
\hline \multicolumn{7}{|c|}{ Cancer mortality (no. of deaths $=1153$ ) } \\
\hline 1st decile $(f<4.5 ; m<4.7)$ & $1.33(1.01,1.75)$ & 0.04 & $1.33(1.00,1.77)$ & 0.05 & $1.29(0.95,1.75)$ & 0.10 \\
\hline 2nd decile (f 4.5-4.8; m 4.7-5.2) & $1.50(1.15,1.97)$ & 0.003 & $1.54(1.17,2.03)$ & 0.002 & $1.52(1.14,2.03)$ & 0.005 \\
\hline 3rd decile (f 4.9-5.3; m 5.3-5.7) & Reference & & Reference & & Reference & \\
\hline 4th decile (f 5.4-5.6; m 5.8-6.0) & $1.05(0.79,1.40)$ & 0.74 & $1.05(0.78,1.41)$ & 0.75 & $1.10(0.81,1.50)$ & 0.52 \\
\hline 5th decile (f 5.7-6.0; m 6.1-.4) & $1.23(0.94,1.61)$ & 0.13 & $1.20(0.91,1.58)$ & 0.20 & $1.19(0.89,1.58)$ & 0.25 \\
\hline 6th decile (f 6.1-6.3; m 6.5-6.8) & $1.02(0.76,1.37)$ & 0.91 & $1.03(0.76,1.39)$ & 0.86 & $0.99(0.72,1.36)$ & 0.94 \\
\hline 7th decile (f 6.4-6.8; m 6.9-7.2) & $1.15(0.88,1.52)$ & 0.30 & $1.14(0.86,1.51)$ & 0.35 & $1.11(0.83,1.49)$ & 0.49 \\
\hline 8th decile (f 6.9-7.3; m 7.3-7.8) & $1.37(1.05,1.78)$ & 0.02 & $1.30(0.99,1.71)$ & 0.06 & $1.28(0.96,1.70)$ & 0.10 \\
\hline 9th decile (f 7.4-8.2; $m$ 7.9-8.7) & $1.36(1.04,1.77)$ & 0.02 & $1.24(0.94,1.63)$ & 0.14 & $1.25(0.94,1.67)$ & 0.13 \\
\hline 10th decile $(f>8.2 ; m>8.8)$ & $1.27(0.97,1.66)$ & 0.09 & $1.13(0.85,1.50)$ & 0.41 & $1.13(0.84,1.52)$ & 0.42 \\
\hline \multicolumn{7}{|c|}{ Respiratory disease mortality (no. of deaths = 325) } \\
\hline 1st decile $(f<4.5 ; m<4.7)$ & $1.23(0.69,2.19)$ & 0.49 & $1.09(0.59,1.99)$ & 0.78 & $1.16(0.62,2.17)$ & 0.64 \\
\hline 2nd decile (f 4.5-4.8; m 4.7-5.2) & $1.19(0.66,2.14)$ & 0.55 & $1.23(0.68,2.22)$ & 0.50 & $1.30(0.70,2.40)$ & 0.41 \\
\hline 3rd decile (f 4.9-5.3; m 5.3-5.7) & Reference & & Reference & & Reference & \\
\hline 4th decile (f 5.4-5.6; m 5.8-6.0) & $1.36(0.78,2.37)$ & 0.28 & $1.41(0.80,2.50)$ & 0.24 & $1.55(0.86,2.79)$ & 0.15 \\
\hline 5th decile (f 5.7-6.0; m 6.1-.4) & $1.44(0.84,2.47)$ & 0.19 & $1.52(0.87,2.64)$ & 0.14 & $1.50(0.83,2.68)$ & 0.18 \\
\hline 6th decile (f 6.1-6.3; m 6.5-6.8) & $1.41(0.80,2.49)$ & 0.23 & $1.47(0.82,2.65)$ & 0.20 & $1.61(0.88,2.95)$ & 0.12 \\
\hline 7th decile (f 6.4-6.8; m 6.9-7.2) & $1.47(0.85,2.52)$ & 0.17 & $1.55(0.89,2.72)$ & 0.12 & $1.53(0.85,2.76)$ & 0.16 \\
\hline 8th decile (f 6.9-7.3; m 7.3-7.8) & $2.07(1.24,3.45)$ & 0.005 & $2.19(1.29,3.72)$ & 0.004 & $2.28(1.31,3.95)$ & 0.003 \\
\hline 9th decile (f 7.4-8.2; $m$ 7.9-8.7) & $1.99(1.19,3.34)$ & 0.01 & $2.25(1.32,3.85)$ & $<0.001$ & $2.26(1.29,3.95)$ & $<0.001$ \\
\hline 10th decile $(f>8.2 ; m>8.8)$ & $2.32(1.41,3.84)$ & 0.001 & $2.52(1.49,4.27)$ & 0.001 & $2.51(1.45,4.35)$ & 0.001 \\
\hline
\end{tabular}

a adjusted for age, sex, education, occupation, smoking status, alcohol use, physical activity, self-rated health, body mass index, diabetes, triglycerides, highdensity lipoprotein cholesterol, platelet count and haemoglobin

Table 4 Association between the baseline white blood cell count and respiratory disease mortality in the Guangzhou Biobank Cohort Study, 2003-2016, excluding deaths within 2 years

\begin{tabular}{|c|c|c|c|c|}
\hline \multirow[t]{2}{*}{$\begin{array}{l}\text { Decile of WBC count, } \\
\times 10^{9} / L \text { (range) }\end{array}$} & \multicolumn{2}{|c|}{$\begin{array}{l}\text { Multivariable model }^{a} \\
(n=29,672)\end{array}$} & \multicolumn{2}{|c|}{$\begin{array}{l}\text { Multivariable model in } \\
\text { non-smokers }{ }^{\text {a }}(n=23,958)\end{array}$} \\
\hline & HR $(95 \% \mathrm{Cl})$ & $P$ value & HR $(95 \% \mathrm{Cl})$ & $P$ value \\
\hline 1st decile $(f<4.5 ; m<4.7)$ & $1.28(0.68,2.41)$ & 0.44 & $1.20(0.52,2.80)$ & 0.67 \\
\hline 2nd decile (f 4.5-4.8; m 4.7-5.2) & $1.21(0.65,2.25)$ & 0.56 & $1.07(0.45,2.54)$ & 0.88 \\
\hline 3rd decile (f 4.9-5.3; m 5.3-5.7) & Reference & & Reference & \\
\hline 4th decile (f 5.4-5.6; m 5.8-6.0) & $1.50(0.83,2.72)$ & 0.18 & $1.51(0.69,3.31)$ & 0.31 \\
\hline 5th decile (f 5.7-6.0; m 6.1-.4) & $1.39(0.78,2.51)$ & 0.27 & $1.45(0.67,3.14)$ & 0.35 \\
\hline 6th decile (f 6.1-6.3; m 6.5-6.8) & $1.49(0.81,2.73)$ & 0.20 & $1.74(0.79,3.85)$ & 0.17 \\
\hline 7th decile (f 6.4-6.8; m 6.9-7.2) & $1.36(0.75,2.46)$ & 0.31 & $1.39(0.64,3.03)$ & 0.40 \\
\hline 8th decile (f 6.9-7.3; m 7.3-7.8) & $1.89(1.08,3.31)$ & 0.03 & $1.91(0.90,4.04)$ & 0.09 \\
\hline 9th decile (f 7.4-8.2; $m$ 7.9-8.7) & $1.99(1.13,3.48)$ & 0.02 & $2.13(1.01,4.48)$ & 0.05 \\
\hline 10th decile $(f>8.2 ; m>8.8)$ & $1.90(1.08,3.33)$ & 0.03 & $1.79(0.83,3.84)$ & 0.14 \\
\hline
\end{tabular}

\footnotetext{
${ }^{a}$ : adjusted for age, sex, education, occupation, smoking status, alcohol use, physical activity, self-rated health, body mass index, diabetes, triglycerides, highdensity lipoprotein cholesterol, platelet count, haemoglobin, force vital capacity (FVC), forced expiratory volume in $1 \mathrm{~s}$ (FEV1), and self-reported respiratory disease (COPD, chronic bronchitis, emphysema, asthma, tuberculosis, pneumonia)
} 
Results of previous prospective cohort studies on the association of WBC count with cancer mortality have been less consistent. We found only 6 studies [1, 3, 7, 30-32], and of them, three showed a positive association [7, 31, 32], two showed no association [1,3] and one showed an inverse association [7]. In a subset of participants in the Multiple Risk Factor Intervention Trial (MRFIT), elevated WBC count was associated with a higher risk of cancer death [31]. A prospective study conducted in postmenopausal women also found the evidence of higher WBC counts associated with higher risk of breast, lung and overall cancer mortality [32]. The other study from Australia also showed a higher risk of cancer mortality in those with high (4th quartile) versus low WBC count (1st quartile group) [7]. However, a large Korean study found no association between WBC count and cancer mortality, although, as expected, it found a significant and robust association with CHD mortality [3]. In a more recent study from the Women's Health Initiative (WHI), the association of WBC count with cancer mortality was weaker than those of all-cause or CHD mortality, and was attenuated toward the null when women with comorbidity and deaths within the first 6 years of follow-up were excluded [1]. Our results also indicate a possible association between lower WBC count and cancer mortality, which was observed in the WHI study and a Taiwan study [30]. Within the normal range, a relatively low WBC count may be an indicator of low immune response which could also increase the risk of cancer mortality, although the underlying mechanisms warrant further investigation. We did not find any evidence supporting an association of higher WBC count with cancer mortality. As some treatment for cancer may lower WBC counts in clinical practice and cancer patients may be more vulnerable to opportunistic pathogens, both are often associated with a higher risk of infection that requires treatment with antibiotics and may affect WBC counts subsequently. However, our sensitivity analysis excluding participants with self-reported cancer history showed similar results.

Our study showed that elevated WBC count was significantly associated with a higher risk of respiratory mortality. Previous large cohort studies suggested that such an association could be due to confounding from smoking [33], i.e., smoking leads to both an elevated WBC count and a higher risk of respiratory mortality [33-35]. Using baseline data of the GBCS, we also found that relative to never smokers, current smokers were associated with a greater WBC count and demonstrated a dose response relationship [36]. However, in the present analysis, the association was still observed in our never smokers, suggesting that smoking was unlikely to account for the findings. One possible mechanism is that systemic inflammation-induced endothelial dysfunction may lead to pulmonary vascular filtration and lung tissue injury [9]. In addition, neutrophils, one type of granulocytes, secrete serine proteases including neutrophil elastase, cathepsin G and proteinase-3, as well as MMP-8 and MMP-9, which may lead to destruction of the alveolar tissue and increase the risk of lung disease [37]. The exact mechanisms underlying the association of WBC count with cause-specific mortality require investigation.

For the association with CVD/CHD, we found six studies [38-43] showing a positive association with granulocyte count, and of them, four showed no association with lymphocyte or monocyte counts [38, 39, 41, 42], and one showed a positive association with monocyte count [40]. A meta-analysis showed that people in the highest, versus those in the lowest, granulocyte quartile had a risk ratio of 1.32 (95\% CI 1.15-1.51) for CHD [44]. Our study is in accordance with this meta-analysis showing that participants with higher granulocyte count were associated with a $69 \%$ higher risk of $\mathrm{CHD}$ mortality. Our results suggest that the increased risk related to WBC count might be partly due to the granulocyte count. Further studies exploring the differentiation, production and function of granulocytes and the related health effects are warranted. Although in our present study, the number of deaths was not sufficient to support more analyses for the subtypes of cardiovascular events, we would follow up all participants to enable more in-depth analysis.

The strengths of this study included the large sample size and comprehensive measurement and adjustment of potential confounding factors. However, there were some limitations. First, as noted above, the number of deaths from cause-specific mortality (especially CHD or respiratory disease) was relatively small. More detailed analyses of specific types of cardiovascular or respiratory disease could not be performed. Moreover, participants in the lower decile groups appeared to have a higher risk of death from all-cause, CHD and respiratory disease, although the results were not statistically significant. As the number of deaths in the lower decile groups were small, further studies are warranted to clarify. Second, as baseline WBC count was measured only at one-time point, the $\mathrm{WBC}$ counts might not accurately indicate a lifelong exposure. Repeated WBC measurements may provide a more reliable measurement of WBC count and minimize potential misclassification of exposure. However, in a recent study in women, similar results were observed using a single baseline measurement and using the average of the measurements at baseline and at the third year [1]. Thus, the lack of repeated measurement in the current study could not have influenced the risk estimation substantially. Third, our results based on prospective observational data cannot confirm a causal relation between WBC count and deaths due to CHD or respiratory disease. But as a predictive biomarker, the results from our study are informative and complementary to the literature. Fourth, although we have adjusted for a range of potential confounding factors, elevated WBC count may 
reflect an inflammatory response due to unknown causes (i.e., underlying chronic diseases or specific exposures that would increase WBC count and mortality at the same time). An alternative newly developed method, Mendelian randomization, might provide a unique opportunity to investigate the direct association, if any, between WBC count and $\mathrm{CHD}$ or respiratory disease. Fifth, women were oversampled in this study, as other population-based elderly cohorts. However, we tested for sex interaction and found no evidence for interaction ( $P$ values for interaction ranged 0.33 to 0.91 ), indicating the association between WBC count and the risk of all-cause and cause-specific mortality did not vary by sex. Moreover, sex was also adjusted in all models to minimize its potential confounding effect. Thus, the unbalanced sex ratio might not be a major concern in the current study. Finally, as all participants in the GBCS were older Chinese from southern China, generalizability may be a concern, although within sex and age group, the participants had fairly similar prevalence of major chronic diseases (i.e., diabetes and hypertension) to nationally representative samples of urban Chinese [11].

\section{Conclusions}

In conclusion, our results provide robust prospective evidence supporting that WBC and specifically granulocyte count is associated with the risk of all-cause, CHD and respiratory mortality. Further investigation is warranted to clarify whether decreases in inflammation would have effects on WBC count associated mortality.

\section{Additional file}

Additional file 1: Table S1. Association between the baseline white blood cell count within normal range $\left(4 \times 10^{9} / \mathrm{L}<\right.$ WBC count $<10 \times 10^{9} /$ $\mathrm{L})$ and total mortality and coronary heart disease (CHD) mortality in the Guangzhou Biobank Cohort Study, 2003-2016; Table S2. Association between the baseline white blood cell count within normal range $(4 \times$ $10^{9} / \mathrm{L}<\mathrm{WBC}$ count $<10 \times 10^{9} / \mathrm{L}$ ) and cancer and respiratory disease mortality in the Guangzhou Biobank Cohort Study, 2003-2016; Table S3. Association between the baseline white blood cell count within normal range $\left(4 \times 10^{9} / \mathrm{L}<\mathrm{WBC}\right.$ count $\left.<10 \times 10^{9} / \mathrm{L}\right)$ and respiratory disease mortality in the Guangzhou Biobank Cohort Study, 2003-2016, excluding deaths within 2 years; Table S4. Association between the baseline white blood cell count and respiratory disease mortality in current smokers in the Guangzhou Biobank Cohort Study, 2003-2016; Table S5. Association between the baseline granulocyte count and total mortality and coronary heart disease (CHD) mortality in the Guangzhou Biobank Cohort Study, 2003-2016; Table S6. Association between the baseline granulocyte count and cancer and respiratory disease mortality in the Guangzhou Biobank Cohort Study, 2003-2016; Table S7. Association between the baseline lymphocyte count and total mortality and coronary heart disease (CHD) mortality in the Guangzhou Biobank Cohort Study, 20032016; Table S8. Association between the baseline lymphocyte count and cancer and respiratory disease mortality in the Guangzhou Biobank Cohort Study, 2003-2016. (DOCX 41 kb)

\section{Abbreviations}

CHD: Coronary heart disease; Cl: Confidence interval; FEV1: Forced expiratory volume in one second; FVC: Forced vital capacity; GBCS: The Guangzhou
Biobank Cohort Study; HRs: Hazard ratios; IPAQ: International Physical Activity Questionnaire; SD: Standard deviation; WBC: White blood cell

\section{Acknowledgments}

The Guangzhou Biobank Cohort Study investigators include: Guangzhou No. 12 Hospital: WS Zhang, M Cao, T Zhu, B Liu, CQ Jiang (Co-Pl); The University of Hong Kong: CM Schooling, SM McGhee, GM Leung, R Fielding, TH Lam (Co-PI); The University of Birmingham: P Adab, GN Thomas, KK Cheng (Co-PI).

\section{Funding}

The Guangzhou Biobank Cohort Study was funded by The University of Hong Kong Foundation for Educational Development and Research (SN/1f) HKUF-DC; C20400.28505200), the Health Medical Research Fund (Grant number: HMRF/13143241) in Hong Kong; the Guangzhou Public Health Bureau (201102A211004011) and the Guangzhou Science and Technology Bureau, Guangzhou, China (2002Z2-E2051; 2012 J5100041; 2013 J4100031); Natural Science Foundation of Guangdong (2015A030313891) and the University of Birmingham, UK.

\section{Availability of data and materials}

Data that support findings are restricted to researchers who have permission from the Guangzhou biobank cohort study, and so are not publicly available. The data that support this analysis may be available on reasonable request from the corresponding author.

\section{Authors' contributions}

TW, LX, THL, GNT, WSZ, FZ, YLJ, CQJ, and KKC have substantial contributions to conception and design, acquisition of funding, data and interpretation of data; TW, LX, CQJ and THL analysed the data, TW, LX, CQJ, THL, GNT and KKC drafted the article, LX, CQJ, THL and KKC revised it critically for important intellectual content. All authors read and approved the final manuscript.

\section{Ethics approval and consent to participate}

The GBCS was approved by Guangzhou Medical Ethics Committee of the Chinese Medical Association. All participants provided written, informed consent before participation.

\section{Consent for publication}

Not applicable

\section{Competing interests}

The authors declare that they have no competing interests.

\section{Publisher's Note}

Springer Nature remains neutral with regard to jurisdictional claims in published maps and institutional affiliations.

\section{Author details}

${ }^{1}$ School of Public Health, Sun Yat-sen University, 2nd Zhongshan RoadGuangdong Province, Guangzhou, China. ${ }^{2}$ Guangzhou No.12 Hospital, Guangzhou 510620, China. ${ }^{3}$ School of Public Health, The University of Hong Kong, Hong Kong, China. Institute of Applied Health Research, University of Birmingham, Birmingham, UK.

Received: 18 June 2018 Accepted: 26 September 2018

Published online: 06 November 2018

\section{References}

1. Kabat GC, Kim MY, Manson JE, Lessin L, Lin J, Wassertheil-Smoller S, Rohan TE. White blood cell count and Total and cause-specific mortality in the Women's health initiative. Am J Epidemiol. 2017;186(1):63-72.

2. Weijenberg MP, Feskens EJ, Kromhout D. White blood cell count and the risk of coronary heart disease and all-cause mortality in elderly men. Arterioscler Thromb Vasc Biol. 1996:16(4):499-503.

3. Jee SH, Park JY, Kim HS, Lee TY, Samet JM. White blood cell count and risk for all-cause, cardiovascular, and cancer mortality in a cohort of Koreans. Am J Epidemiol. 2005;162(11):1062-9.

4. Tamakoshi K, Toyoshima H, Yatsuya H, Matsushita K, Okamura T, Hayakawa T, Okayama A, Ueshima H, Group NDR. White blood cell count and risk of all-cause and cardiovascular mortality in nationwide sample of Japanese-results from the NIPPON DATA90. Circ J. 2007;71(4):479-85. 
5. Brown DW, Giles WH, Croft JB. White blood cell count: An independent predictor of coronary heart disease mortality among a national cohort. J Clin Epidemiol. 2001;54(3):316-22

6. Gillum RF, Ingram DD, Makuc DM. White blood cell count and stroke incidence and death. The NHANES I epidemiologic follow-up study. Am J Epidemiol. 1994;139(9):894-902.

7. Shankar A, Wang JJ, Rochtchina E, Yu MC, Kefford R, Mitchell P. Association between circulating white blood cell count and cancer mortality - a population-based cohort study. Arch Intern Med. 2006;166(2):188-94.

8. Qiao R, Yang S, Yao B, Wang H, Zhang J, Shang H. Complete blood count reference intervals and age- and sex-related trends of North China Han population. Clin Chem Lab Med. 2014;52(7):1025-32.

9. Yang HF, Kao TW, Wang CC, Peng TC, Chang YW, Chen WL. Serum white blood cell count and pulmonary function test are negatively associated. Acta Clin Belg. 2015;70(6):419-24.

10. McKeever T, Saha S, Fogarty AW. The association between systemic inflammatory cellular levels and lung function: a population-based study. PLoS One. 2011;6(7):e21593.

11. Jiang C, Thomas GN, Lam TH, Schooling CM, Zhang W, Lao X, Adab P, Liu B, Leung GM, Cheng KK. Cohort profile: the Guangzhou biobank cohort study, a Guangzhou-Hong Kong-Birmingham collaboration. Int J Epidemiol. 2006; 35(4):844-52.

12. Deng HB, Macfarlane DJ, Thomas GN, Lao XQ, Jiang CQ, Cheng KK, Lam TH, Reliability and validity of the IPAQ-Chinese: the Guangzhou biobank cohort study. Med Sci Sports Exerc. 2008:40(2):303-7.

13. Jiang CQ, Lao XQ, Yin P, Thomas GN, Zhang WS, Liu B, Adab P, Lam $\mathrm{TH}$, Cheng KK. Smoking, smoking cessation and aortic arch calcification in older Chinese: the Guangzhou biobank cohort study. Atherosclerosis. 2009;202(2):529-34.

14. Yin P, Jiang CQ, Cheng KK, Lam TH, Lam KH, Miller MR, Zhang WS, Thomas GN, Adab P. Passive smoking exposure and risk of COPD among adults in China: the Guangzhou biobank cohort study. Lancet. 2007;370(9589):751-7.

15. Welsh C, Welsh P, Mark PB, Celis-Morales CA, Lewsey J, Gray SR, Lyall DM, Iliodromiti S, Gill JMR, Pell J, et al. Association of Total and Differential Leukocyte Counts with Cardiovascular Disease and mortality in the UK biobank. Arterioscler Thromb Vasc Biol. 2018;38(6):1415-23.

16. Ruggiero C, Metter EJ, Cherubini A, Maggio M, Sen R, Najjar SS, Windham GB, Ble A, Senin U, Ferrucci L. White blood cell count and mortality in the Baltimore longitudinal study of aging. J Am Coll Cardiol. 2007;49(18):1841-50.

17. Nilsson G, Hedberg P, Ohrvik J. White blood cell count in elderly is clinically useful in predicting long-term survival. J Aging Res. 2014;2014:475093.

18. Fan X, Huang B, Lu H, Zhao Z, Lu Z, Yang Y, Zhang S, Hui R. Impact of admission white blood cell count on short- and long-term mortality in patients with type a acute aortic dissection: an observational study. Medicine. 2015;94(42):e1761.

19. Venetz C, Labarere J, Jimenez D, Aujesky D. White blood cell count and mortality in patients with acute pulmonary embolism. Am J Hematol. 2013; 88(8):677-81.

20. Stewart RA, White HD, Kirby AC, Heritier SR, Simes RJ, Nestel PJ, West MJ, Colquhoun DM, Tonkin AM. Long-term intervention with pravastatin in ischemic disease study I: white blood cell count predicts reduction in coronary heart disease mortality with pravastatin. Circulation. 2005;111(14): 1756-62.

21. Mueller C, Neumann FJ, Perruchoud AP, Buettner HJ. White blood cell count and long term mortality after non-ST elevation acute coronary syndrome treated with very early revascularisation. Heart. 2003;89(4):389-92.

22. Lee CD, Folsom AR, Nieto FJ, Chambless LE, Shahar E, Wolfe DA. White blood cell count and incidence of coronary heart disease and ischemic stroke and mortality from cardiovascular disease in African-American and white men and women: atherosclerosis risk in communities study. Am J Epidemiol. 2001;154(8):758-64.

23. Manttari M, Manninen V, Koskinen P, Huttunen JK, Oksanen E, Tenkanen L, Heinonen OP, Frick MH. Leukocytes as a coronary risk factor in a dyslipidemic male population. Am Heart J. 1992;123(4 Pt 1):873-7.

24. Madjid M, Awan I, Willerson JT, Casscells SW. Leukocyte count and coronary heart disease: implications for risk assessment. J Am Coll Cardiol. 2004; 44(10):1945-56.

25. Walker AE, Seibert SM, Donato AJ, Pierce GL, Seals DR. Vascular endothelia function is related to white blood cell count and myeloperoxidase among healthy middle-aged and older adults. Hypertension. 2010;55(2):363-9.
26. Moilanen $\mathrm{E}$, Vapaatalo $\mathrm{H}$. Nitric oxide in inflammation and immune response. Ann Med. 1995:27(3):359-67.

27. Shankar A, Klein BEK, Klein R. Relationship between white blood cell count and incident hypertension. Am J Hypertens. 2004;17(3):233-9.

28. Karthikeyan VJ, Lip GYH. White blood cell count and hypertension commentary. J Hum Hypertens. 2006;20(5):310-2.

29. Lao XQ, Neil Thomas G, Jiang C, Zhang W, Adab P, Lam TH, Cheng KK. White blood cell count and the metabolic syndrome in older Chinese: the Guangzhou biobank cohort study. Atherosclerosis. 2008;201(2):418-24.

30. Huang ZS, Chien KL, Yang CY, Wang CH, Chang TC, Chen CJ. Peripheral differential leukocyte counts and subsequent mortality from all diseases, cancers, and cardiovascular diseases in Taiwanese. J Formos Med Assoc. 2003:102(11):775-81.

31. Grimm RH Jr, Neaton JD, Ludwig W. Prognostic importance of the white blood cell count for coronary, cancer, and all-cause mortality. Jama. 1985; 254(14):1932-7.

32. Margolis KL, Rodabough RJ, Thomson CA, Lopez AM, McTiernan A. Prospective study of leukocyte count as a predictor of incident breast, colorectal, endometrial, and lung cancer and mortality in postmenopausal women. Arch Intern Med. 2007;167(17):1837-44.

33. Anderson DO, Ferris BG Jr. Role of tobacco smoking in the causation of chronic respiratory disease. N Engl J Med. 1962;267:787-94.

34. Hogarty V, May H, Khaw KT. White blood cell count, blood pressure, and cigarette smoking in older adults. J Am Geriatr Soc. 1995:43(7):837-8.

35. Taylor RG, Gross E, Joyce H, Holland F, Pride NB. Smoking, allergy, and the differential white blood cell count. Thorax. 1985:40(1):17-22.

36. Lao XQ, Jiang CQ, Zhang WS, Adab P, Lam TH, Cheng KK, Thomas GN. Smoking, smoking cessation and inflammatory markers in older Chinese men: the Guangzhou biobank cohort study. Atherosclerosis. 2009;203(1):304-10.

37. Barnes PJ. Inflammatory mechanisms in patients with chronic obstructive pulmonary disease. J Allergy Clin Immunol. 2016;138(1):16-27.

38. Gillum RF, Mussolino ME, Madans JH. Counts of neutrophils, lymphocytes, and monocytes, cause-specific mortality and coronary heart disease: the NHANES-I epidemiologic follow-up study. Ann Epidemiol. 2005;15(4):266-71.

39. Rana JS, Boekholdt SM, Ridker PM, Jukema JW, Luben R, Bingham SA, Day NE, Wareham NJ, Kastelein JJ, Khaw KT. Differential leucocyte count and the risk of future coronary artery disease in healthy men and women: the EPICNorfolk prospective population study. J Intern Med. 2007;262(6):678-89.

40. Kim Kl, Lee J, Heo NJ, Kim S, Chin HJ, Na KY, Chae DW, Kim CH, Kim S. Differential white blood cell count and all-cause mortality in the Korean elderly. Exp Gerontol. 2013;48(2):103-8.

41. Karino S, Willcox BJ, Fong K, Lo S, Abbott R, Masaki KH. Total and differential white blood cell counts predict eight-year incident coronary heart disease in elderly Japanese-American men: the Honolulu heart program. Atherosclerosis. 2015;238(2):153-8.

42. O Hartaigh B, Bosch JA, Thomas GN, Lord JM, Pilz S, Loerbroks A, Kleber ME, Grammer TB, Fischer JE, Boehm BO, et al. Which leukocyte subsets predict cardiovascular mortality? From the LUdwigshafen Rlsk and cardiovascular health (LURIC) study. Atherosclerosis. 2012;224(1):161-9.

43. Chmielewski PP, Boryslawski K, Chmielowiec K, Chmielowiec J, Strzelec B. The association between total leukocyte count and longevity: evidence from longitudinal and cross-sectional data. Ann Anat. 2016:204:1-10.

44. Wheeler JG, Mussolino ME, Gillum RF, Danesh J. Associations between differential leucocyte count and incident coronary heart disease: 1764 incident cases from seven prospective studies of 30374 individuals. Eur Heart J. 2004;25(15):1287-92

\section{Ready to submit your research? Choose BMC and benefit from:}

- fast, convenient online submission

- thorough peer review by experienced researchers in your field

- rapid publication on acceptance

- support for research data, including large and complex data types

- gold Open Access which fosters wider collaboration and increased citations

- maximum visibility for your research: over $100 \mathrm{M}$ website views per year

At $\mathrm{BMC}$, research is always in progress.

Learn more biomedcentral.com/submissions 